\title{
Tourism Policies and Strategies: Vital in the Actual Security Constrains Context
}

\author{
Diana Foris \\ Food and Tourism Faculty, Transilvania University, Romania
}

Copyright $(2016$ by authors, all rights reserved. Authors agree that this article remains permanently open access under the terms of the Creative Commons Attribution License 4.0 International License

\begin{abstract}
The study deals with the importance of public policies and strategies for tourism in the context of the current situation of insecurity generated by the terrorist attacks. Reviewing the current tense situation, the terrorist threat is growing, thus we identify the effects on tourism and travel. Analyzing the factors that may cause the intensification or reduction of tourism development is carried out through the prism of their coverage under the public policy upon tourism, as well as the influence of these factors relating to their employment with the impact on tourism in the category of stimulating factors or those of constraints, favoring the aspects that determine or brake tourism. In this respect, it is analyzed the influence of public policies of investments in general and touristic infrastructure, of public policies with social component, of public policies with an organizational - administrative component and of public policies with political component. It is analyzed the need of security policies, public policies with a political component, with the organizational and administrative component of government policies to ensure the development of tourism and travel industry. In light of, we focus on the strategies on the national tourism master and marketing plans, in an analysis of the situation at the international level.
\end{abstract}

Keywords Tourism, Public Policies, Tourism Strategies, Stimulating Factors, Security Constraints, National Tourism Master and Marketing Plans

\section{Introduction}

Tourism is a complex phenomenon, which may constitute an important source of development and recovery of the national economies of countries that have resources and that they properly exploite.

For example, tourism is the major source of income for countries such as Bermuda, Greece, Italy, Spain, Switzerland and most Caribbean countries...It is a growth industry of increasing power, influence and importance, highly competitive in both a national and international sense.[1]

Regarding the current situation and what future aticipates on tourism and travel industry, the involvement and training of the state and governance is more necessary than ever.

Thus, the major implications of the implementation of the tourism domain in a country's economy require the involvement of the state in order to define and implement coherent policies and strategies in tourism.

Nowadays, in addition to the classic arguments which plead for an intervention of the state in tourism: international competition in the field, national interests, the necessity of linking the tourism with the evolution of other branches of the national economy and the complexity of features specific to the tourism industry, a new argument looming in the context of the current situation of insecurity generated by the terrorist attacks.

In this sense, we argue that, in the last period of time, the international press had reported on a number of topics on the subject of terrorist attacks carried out in the world. The world is currently experiencing a tense political situation, where the terrorist threat has become larger.

Until november 13, 289 terrorist attacks were recorded in the world, most being recorded in countries such as Turkey, Nigeria, Pakistan, Egypt, Syria, Iraq and Saudi Arabia [2], to those we may also added the one from 14.11.2015 in Paris and the one from 20.11.2015 in Mali.

We will make a further review of some of the main events of this kind that have occurred during the year 2015 and already producing effects on tourism and travel industry. In Mali, to a hotel, where they were accommodated foreign tourists were held hostage for hours and resulted human casualties. In Tunisia: bloody bombing against Bardo Museum of Tunis in March 2015, and three months later, the attack on foreign tourists that stayed in a hotel in the resort of Sousse, in both attacks there were wounded and resulted with human casualties. In Egypt, the bombing from Luxor, one of the favorite tourist destinations of foreign tourists, which have not resulted with casualties among tourists, and also the terrorist bombing of the Boeing 737, which led to the plane crush, the plane carrying Russian tourists who were going from Egyptian Resort Sharm el-Sheikh to St. Petersburg, and 
resulted the death of over 200 people. In Turkey, the double assassination committed in October near the central train station of Ankara, before a peace rally, resulting human casualties. In France, after the attack on Charlie Hebdo magazine resulted with human casualties in January, and the victim trying to open fire in the Thalys train which ran on the route Amsterdam-Paris in august, resulting injured persons, the bombing in November in Paris, rocked the world, through multiple attacks at the same time that took place in the Stade de France and Bichat, Charonne and Bataclan, resulting in many casualties.

Analyzing the main terrorist attacks committed in France in recent years [3], we observe that if in the years 2012, 2013 and 2014 it was regeistered an attempt, in 2015 there were recorded 7 attacks.

After these terrorist attacks, tourism related destinations affected decreases with a felt recoil both in annualized figures concerning the number of tourists and revenue in foreign currency, so at the level of international tourism.

Of course, in this context, it is necessary the state intervention as well as for security policies which lead to the eliminating the situation of insecurity generated by the terrorist attacks, but also in public policies to ensure the development of tourism, while at the same time linking macroeconomic developments in relation to all other branches. Policy implementation is facilitated by public involvement in decision making. [4]

\section{Materials and Methods}

The research methodology involved activities of collection, processing and interpretation of information on the issue of the public policies and their impact on tourism activities in many states, using a large documentary material (books, studies, magazines, legislative regulations, database information available through Internet etc.), making analytical and objective observations, theoretical analysis and content analysis.

\section{Public Policies and Strategies for Tourism Development}

Tourism evolution is influenced by the incidence of several factors, different as nature and role, which can determine increasing or decreasing of the activity. Among the many classifications of these factors existing in tourism theory [5], one of the most important and comprehensive groups has as criteria their contents or nature. From this point of view, are indicated:

a). Social - economic factors

1. Economic factors:

- level of socio-economic development, illustrated by GNP / capita;

- Tourism household income and availability;

- prices and interest rates products;
- touristic offer.

2. Technical factors:

- general and touristic infrastructure: highways, moderns roads, bridges, means of transportation, telecommunication, electric and thermic energy, water, sewage, fuel etc.;

- technical facilities of structures with functions of tourist accommodation, food.

3. Social factors:

- degree of urbanization;

- weekly and yearly spare time;

- unemployment;

- social protection etc.

b). Psycho-demographic factors:

- Demographic factors: numerical evolution of population; changing life expectancy; structure by sex and age group; structure by socio professional categories etc.;

- Psychological and educational factors: knowledge willingness; temperament; individual character; fashion; level of education; touristic motivation in evolution; attitudes; enriching the touristic experience etc.

c). Administrative - organizational factors: customs clearance; visas condition; safety of tourists, typological diversity of arrangements; facilities or priorities in organized tourism; participation at world touristic calendar etc.

d). Political factors (internal and external): bilateral agreements between states; general treats; UN conferences on touristic theme; regional agreements; ensuring free movement of tourists as an effect of a political understanding; reconsidering the tourism symbol as "barometer of political situation in a country" and as "passport for peace".

Knowing the factors which determine and bring forward the tourism or, on the contrary, have effects of relative braking over this, it has a great importance in the development of this sector.

To cultivate tourism's potential there is a need to develop in parallel tourism and other public policies designed to sustain and enhance peoples' economic and social well fare, their way of life and their culture [1].

Further, analyzing the impact of public policies on tourism [6], we notice that these factors of incidence on tourism can be influenced by being included in the category of stimulated factors or constraints, aspects which are pro or against tourism.

Public policies of growing the level of socio - economic development, illustrated by GNP / capita and population income will lead to increasing the availability for tourism, which determines including the economic factors among the stimulating factors of tourism development, contrary to the public policy of austerity, illustrated by lower household income, aspect which can determine the behavior of these factors as the constraints of the development of the field (constraints of demand contracted by price, income, purchasing power). 
Public policies of investments in general and tourist infrastructure can lead to including technical factors among the stimulating factors of tourism development, in contrast to their absence, leading to the existence of inadequate infrastructure, inadequate reception capacity of an area and limitation of the number of visitors who can move to an area without causing damage to the environment, bad transportation, causing both offer constraints (regarding the limited quantitative character of attractive tourism resources) as well as time constraints (regarding the season length and time travel ) of tourism activities.

Public policies of a social component, of increasing the degree of urbanization, of spare time of population, of unemployment decrease and the existence of social protection determine considering the social factors as stimulating factors of tourism development, opposed to their nonentity which leads to request constraints (of consumers reported to contracted quantity according to the price, income, purchasing power), internal individual constraints (limitation of financial, human, managerial, technical resources of contractors) and of some time constraints (are reflected both in the consumers' limited time off and in the length of touristic season), which can influence the tourism development and the profitability of touristic activity in a negative way. As well, the public policies with a social component, of population's demographic growth, of average length life and educational, can determine restraints requests of consumers reported to the contracted quantity and lack of knowledge, aspects, that, as well, can influence in a negative way the profitability of the tourist activity.

Public policies with administrative-organizational component, of facilitation of administrative bureaucracy (legal, taxes), duty goods, sanitary, of concern regarding the tourists safety and ensuring of facilities or priorities in organized tourism and for participating at world's touristic calendar determine the consideration of administrative organizational factors as stimulators of tourism development, in contrast with the existence of a law in the field of tourism (law restrictions which enclose travelling) and of some governmental politics (nationalization of receptive tourism, state monopoly in touristic activities, overtaxing, complicating and aggravating the administrative formalities, customs, sanitary) incoherent and inadequate, which constitute an inhibiting factor of tourism in the development of tourism.

Public policies with a political component, closing bilateral agreements and treaties between states, concluding regional agreements, ensuring the free movement of tourists as a result of a political agreement, are likely to lead to including political factors among stimulating factors of tourism development, as opposed to the existence of political and security constraints (internal instability of a country's engagement in armed conflict) that compromise national tourism industry, the existence of conflicts and insecurity worldwide, which are inhibitors of the tourism phenomenon in general.

Development and implementation of public policies with impact on tourism is the task of governance, which should be effected through positive influence policies and through cooperation with decision makers, employers 'organizations, trade unions, civic and professional.

Government should treat tourism as an equally significant industry in relative terms to other industries...there is an enduring tourism industry sensitivity manifested by frustration that those who devise and legislate on public policy that affects tourism directly or indirectly, accord less status to it than to other policies [1].

The changing nature of the tourism industry, with its move away from mass tourism towards greater market segmentation, use of new technologies, differentiation of the product and adoption of new management styles, demands a change in the substance of governments' tourism policies [7].

In the context of the current international situation, tourism and hospitality industry are needed both for security policies which would lead to the elimination of the situation of insecurity generated by the terrorist attacks, but also in government policies to ensure the development of this sector.

Of course that public policies are necessary so that the political component to eliminate the existence of the current political and security constraints (arising from terrorist attacks) which jeopardize tourism industries, affected by this state of affairs, both at national and regional (for example, at the level of European Union), but we must signalized this fact for future: the existence of continuing conflicts and of worldwide insecurity may lead to the inhibition of the tourist phenomenon in general.

It is also necessary to reconsider public policies with organizational-administrative component, in order to facilitate administrative formalities, customs, concerns about the safety of tourists, but nevertheless it must be taken into account that the approach of a possible new legislation in the field of tourism, but not with legislative provisions that affects journeys. Undesirable for tourism are inadequate government policies that lead to complicated administrative formalities and slows down, customs, sanitary aspects constitute a factor of tourism development inhibitor.

Turning to government policies and strategies to ensure the development of the tourism industry, we can continue on the national tourism master and marketing plans.

The national tourism master and marketing plans are strategic integrated documents which will form the basis for planning and investment strategies for the development and also for tourism promotion, to the level of a state, and for a certain period of time. Thus, we analyze hereinafter, the existence of these types of strategic documents across states, as well as issues related to the timeliness and the period that they can be applied.

Analyzing the Repository of National Tourism Master and Marketing Plans - Update: May 2015 [8], regarding the Repository of National Tourism Master Plans, who includes a list of the publicly available links of the national tourism master plans and it refers to the publication year of the plan 
and period in which the plan is active, we note that, that from the 220 countries considered, 70 States have developed national tourism master plans. Thus, at the level of their division on geographic region, we find national tourism master plans in 19 countries in Africa (example Morocco, Botswana, Burkina Faso, Cabo Verde, Eritreea, Gambia, Ghana, Malawi, Moyambique, Nigeria, Rwanda, Senegal, Sierra Leone, South Africa, Swailand, Uganda, United Republic of Tanyania and Zimbabwe), in 17 States of American continent (example Mexico, United States of America, Bermuda, Curacao, Haiti, Jamaica, Trinidad and Tobago, Guatemala, Honduras, Panama, Chile, Brazil, Colombia, Ecuador, Paraguay, Peru and Uruguay), in Asia and the Pacific in 11 countries (example Korea, Lao Peoples Democratic Republic, Myanmar, Guam, Northern Mariana Islands, New Zealand, Papua New Guinea, Vanuatu, India, Nepal and Sri Lanka), in Europe in 19 states (example Finland, Iceland, Sweden, Austria, Monaco, Armenia, Hungary, Republic of Moldova, Romania, Slovakia, Turkmenistan, Croatia, Cyprus, Malta, Montenegro, Portugal, Slovenia, Spain and Turkey), and at the level of the Middle East in 4 States (example Jordan, Qatar, Saudi Arabia and Yemen).

Analyzing the publication year of the plan, we notice that 49 of the master plans have been drawn up before 2012 . More recent plans lies in 21 States, namely in 2012 so far, of which 9 in the year 2012, 10 in 2013, the last two being developed in 2014 (example Haiti and Guam).

Regarding the period in which the plan is active, in 24 of these states this is expired (example in Slovenia from 2006, in Cyprus from 2010, in Burkina Faso from 2012, in Slovakia, Monaco and Cabo Verde from 2013), and concerning the implementation of these plans for a longer period of time, we observe only 24 master plans of which reaches or exceeds 2020 (example in Jamaica, Armenia and Qatar to 2030, in Ghana to 2027, in Romania to 2026, in Turkey to 2023, in Bermuda to 2022, in United States of America, Honduras and Peru to 2021).

We believe that all interested states to develop tourism, it is necessary to elaborate a national tourism master plan, that takes into account both the present situation and potential of this sector for the future. In this respect, we refer to those states which have not yet developed such a plan, as well as to the States which have drafted such a plan, but its implementation period is expired.

It is also important that states that have implements a master plan for tourism, to update it, from the point of view of the content in terms of current constraints and potential factors limiting the meaning of the promoters of these constraints. Furthermore, it is necessary to update the tourism vision over the medium and long term, making it desirable for the master plan to include a minimum of 10 years.

Analyzing the Repository of National Tourism Maketings Plans, that includes a list of the publicly available links of the national tourism marketing plans and it refers to the publication year of the plan, period in which the plan is active and languages in which it is available, we note that of all the states considered, only 35 countries have developed tourism maketing plans. At the level of divison of those on geographical regions, we find tourism marketing plans in 5 states from Africa (example Algeria, Tunisia, Cabo Verde, Ghana and Swaziland), in 9 states of American continent (example Canada, Mexico, United States of America, Jamaica, Argentina, Brazil, Colombia, Ecuador and Paraguay), in Asia and the Pacific in 11 Countries (example Japan, Korea, , Lao Peoples Democratic Republic, Myanmar, Vietnam, New Zealand, Bangladesh, Maldives, Nepal and Sri Lanka), in Europe in 9 states (example Norway, Austria, Switzerland, Czech Republic, Hungary, Latvia, Greece, Slovenia and Spain), and at the level of the Middle East in a single state (example Yemen).

Analyzing the publication year of the plan, e observe that 13 of marketing plans have been drawn up before the year 2012. The latest plan is contained in 12 States, namely in 2012 so far, from which 2 in 2012, 6 in 2013, the last 4 being developed in 2014 (example Korea, New Zeeland, Austria and Spain).

Regarding to the period in which the plan is active, in 6 states it is expired (example in Jamaica from 2005, in Slovenia from 2011, in Ghana from 2012, in Cabo Verde from 2013), and concerning the implementation of these plans for a longer period of time, we note that in 4 States which included plans to achieve or exceed in 2020 (example in Yemen to 2025, in Brazil, Nepal and Greece to 2020).

Regarding to the planning of yearly or multi-yearly national marketing plans, an annual planning is included in 20 states, and a multiannual planning in 15 countries: in 3 years in 7 states, in 5 years in 3 countries and in 10 or more years in 5 states.

For the promotion of tourism, it is important to state development and the implementation of national tourism marketing plan, provided, that it is done so that to take into account both the present situation of the market and the potential for the future.

Tasks' administration in a field, namely tourism, by the ministry or by another organ specialized in ministerial administration at the local level (as a manifestation of the principle of decentralization) and/or at a non-governmental level, is an option of the political party or coalition of parties in government, decision expressing the interests of policy priorities. [6]

Taking into consideration the importance of tourism increase from economic, social, cultural points of view, lately, tourism is found in political platforms, governmental programs of political majority, which leads to finding the importance of tourism industry growing in terms of political interest. [6]

In some states (example New Zeeland), public sector policy initiatives indicate a shift towards a more pro-active role for the local state (local and regional government) in managing tourism development. This shift, informed by a New Regionalism policy framework, anticipates a devolved tourism planning mandate that fosters longer-term strategic 
and collaborative planning of the sector in order to enhance the contribution of tourism to sustainable community wellbeing. [9]

Tourism is of great economic importance and significance and for the local development in European regions. In the last few decades there have been noticed often included substantial supporting of institutionalized tourism organizations by tourism policy, with the intention to bundle forces and to achieve growing global competition. Change in international tourist markets demands the pursuance of completely new strategies. [10]

In the present context, it is necessary to implement new tourism development strategies, both nationally and regionally, in line with new public policies that stimulate the development of tourism and to reduce as far as possible the constraints.

\section{Conclusions}

Regarding the current geopolitical context, when the world is facing a tense political situation, where the terrorist threat is becoming larger, and other undesirable aspects that seem to foreshadow the future for the tourism and travel industry, and the involvement and training of the State and governance is more necessary than ever. We notice an intensified terrorist attacks, with the effects on tourism and travel, especially at the level of the affected destinations, which will drive decreases with a recoil both in annualised figures concerning the number of tourists and revenue in foreign currency, so at the level of international tourism

It must be drawn attention upon the future of tourism: continuing existence of conflicts and insecurity worldwide may lead to inhibition of the tourist phenomenon in general.

In the context of the current international situation, tourism and travel industry are needed both for security policies which would lead to the elimination of the situation of insecurity generated by the terrorist attacks, but also in government policies to ensure the development of this sector.

The reconsideration of public policies with the organizational-administrative component, in order to facilitate the administrative formalities, customs, concerns about the safety of tourists, should avoid tackling a possible new legislation that contains legislative provisions that affects trips, which give rise to undesirable effects for tourism and travel industry.

Regarding to the government policies for the development of the tourism industry, we draw attention to the importance of the development and updating of the national tourism master and marketing plans, in terms of content related to the existence of the current constraints and potential factors limiting the meaning of the promoters of these constraints.

We consider necessary and update tourism vision over a medium and long term, in the light of all its components: economic, social, cultural, environmental, security issues, education, information technology, planning, policy, communication, organizational-administrative etc., in the context of tourism consideration as one of the factors for the development of society.

\section{REFERENCES}

[1] W. R. Kerr: Tourism Public Policy, and the Strategic Management of Failure, Advances inTourism Research Series, Pergamon, Elsevier Ltd, Oxford, pp. 10, 2003.

[2] The world is preparing for war! 2015 brought 289 of terrorist attacks, and the threat grows! Online available from http://www.antena3.ro/actualitate/razboi-atentate-teroriste-3 24705.html - consulted at 21.11.2015

[3] Cronology: Major terrorist attacks committed in France in recent years Online available from http://www.mediafax.ro/externe/cronologie-principalele-atac uri-teroriste-comise-in-franta-in-ultimii-ani-14885882 consulted at 21.11.2015

[4] J.J. Pigram: Sustainable tourism - policy considerations, Journal of Tourism Studies, Vol. 1 No. 2 pp. 2-9, 1990.

[5] I. Ionescu: Tourism as economical, social and cultural phenomena (Turismul fenomen economic, social şi cultural), Oscar Print Publishing House, Bucharest, 2000.

[6] D. Foris: Study Regarding the Impact of Public Polices on Tourism Activities, International Conference on Hospitality \& Tourism Management (ICOHT 2013) Sri Lanka, Published by ICOHT 2013 and Leap Business Management, pp. 602-607, 2013.

[7] E. Fayos-Sola: Tourism policy: a midsummer night' dream?, Tourism Management, Volume 17, Issue 6, pp. 405-412, 1996.

[8] World Tourism Organization, Repository of National Tourism Master and Marketing Plans - Update: May 2015, UNWTO, Madrid, 2015.

[9] M.C. Shone, A.P. Memon: Tourism, Public Policy and Regional Development: A Turn from Neo-liberalism to the New Regionalism, Local Economy, Volume 23, Issue 4, pp. 290-304, 2008.

[10] H. Pechlaner, P. Tschurtschenthaler: Tourism Policy, Tourism Organisations and Change Management in Alpine Regions and Destinations: A European Perspective, Current Issues in Tourism, Volume 6, Issue 6, pp. 508-539, 2003 